\title{
Adolescents Adjudicated for Sexual Offending: Differences Between Sexual Reoffenders and Sexual Non-Reoffenders
}

Sandra Siria ${ }^{\mathrm{a}}$, Enrique Echeburúa ${ }^{\mathrm{a}}$, and Pedro J. Amor ${ }^{\mathrm{b}}$

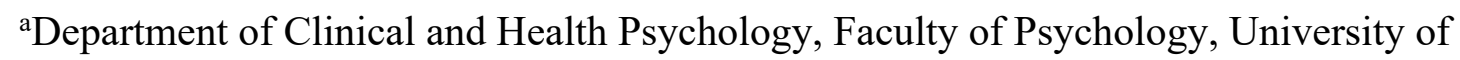
the Basque Country (UPV/EHU), Avenida de Tolosa, 70, 20018, San Sebastián, Spain.

${ }^{\text {b} D e p a r t m e n t ~ o f ~ P e r s o n a l i t y, ~ A s s e s s m e n t, ~ a n d ~ P s y c h o l o g i c a l ~ T r e a t m e n t, ~ F a c u l t a d ~ d e ~}$ Psicología, Universidad Nacional de Educación a Distancia (UNED), c/ Juan del Rosal, 10, 28040, Madrid, Spain.

Acknowledgements: We would like to thank the Spanish Juvenile Justice System authorities that gave permission and made this research possible. We would also like to thank the staff of all the services for their assistance during the duration of this study. Funding information: This research did not receive any specific grant from funding agencies in the public, commercial, or not-for-profit sectors.

Conflict of interest: None.

Corresponding author: Sandra Siria. Department of Health Sciences, Universidad Pública de Navarra, Campus de Arrosadía, Edificio Los Magnolios, 31006, Pamplona, Spain. Email: sandra.siria@unavarra.es

Siria, S., Echeburúa, E., \& Amor, P. J. (in press). Adolescents Adjudicated for Sexual Offending: Differences Between Sexual Reoffenders and Sexual Non-Reoffenders. Journal of Interpersonal Violence. https://doi.org/10.1177/08862605211015209 


\begin{abstract}
Although a very small group of adolescents adjudicated for sexual offending (ASO) will persist into adulthood, the use of official records of sexual recidivism after long-term follow-up periods underrates the repetition of sexually coercive behaviors during adolescence. Additionally, limited research has considered sexual reoffending as a criterion to classify this heterogeneous population. The aims of this study were to determine the prevalence of ASO who engaged in repetitive sexual offending before their adjudication, and to use it as a classification criterion to examine the differential characteristics associated with each group. A sample of 73 adjudicated ASO in Spain was examined. They were divided into sexual reoffenders $(\mathrm{SR})(n=34)$ and sexual nonreoffenders $(\mathrm{SNR})(n=39)$. An ex post facto research design was carried out.

Assessments included reviews of official files, interviews with professionals in charge, and interviews with the ASO in which the Interpersonal Reactivity Index (IRI) was administered. Descriptive analyses were conducted for all variables and Odds Ratio $(O R)$ was used to compare intergroup differences. Results showed that SR had 12.95 times the odds of sexual victimization, 6.91 times the odds of having lived in a sexualized family environment, and 3 times the odds of bullying victimization. Deviant sexual fantasies were exclusively present among SR (44\%). Significant differences between groups were also found in some sexual crime variables but not on the empathy scale. These results have implications for the distinction between ASO who have repeatedly engaged in sexually coercive behavior and those who engaged in a single event of sexual offending. The identification of specific risk factors and criminogenic needs for each group would benefit court decisions and more tailored interventions.

Siria, S., Echeburúa, E., \& Amor, P. J. (in press). Adolescents Adjudicated for Sexual Offending: Differences Between Sexual Reoffenders and Sexual Non-Reoffenders. Journal of Interpersonal Violence. https://doi.org/10.1177/08862605211015209
\end{abstract}


Keywords: adolescent sexual offending, repetitive sexual offending, sexual development, risk factor, empathy

Siria, S., Echeburúa, E., \& Amor, P. J. (in press). Adolescents Adjudicated for Sexual Offending: Differences Between Sexual Reoffenders and Sexual Non-Reoffenders. Journal of Interpersonal Violence. https://doi.org/10.1177/08862605211015209 


\section{Adolescents Adjudicated for Sexual Offending: Differences Between Sexual}

\section{Reoffenders and Sexual Non-Reoffenders}

\section{Introduction}

Research about adolescents adjudicated for sexual offending (ASO) has widely explored the heterogeneity of this population to identify differential characteristics between subgroups (Cale et al., 2016; Fox \& DeLisi, 2018). In this sense, the classification criteria to establish subgroups of ASO are varied among studies. Some of the most commonly used have been those concerning victim's age (Keelan \& Fremouw, 2013; Lillard et al., 2020), additional nonsexual offenses (Butler \& Seto, 2002; Zeng et al., 2015), offenders' personality profiles (Newman et al., 2019; Oxnam \& Vess, 2008), and number of offenders (Hart-Kerkhoffs et al., 2009; Kjellgren et al., 2006). These classifications have provided a useful framework to identify different characteristics, etiological factors, trajectories of offending, and treatment needs (Rajlic \& Gretton, 2010). More precisely, one of the main aims of the studies establishing subgroups of ASO is to help reduce recidivism risk (Fox \& DeLisi, 2018; Kemper \& Kistner, 2010). But limited research has used sexual reoffending as a criterion to classify this population (Kenny et al., 2001).

Recidivism itself has been a major focus of research on ASO (Caldwell, 2016; Kettrey \& Lipsey, 2018). Several studies have tried to quantify recidivism rates as well as to identify those risk factors that could be associated with sexual and general reoffending among ASO, with relevant findings (Calleja, 2015; Christiansen \& Vincent, 2013; Mallie et al., 2011; Worling \& Langstrom, 2006). What seems to be largely demonstrated is that ASO are much more likely to reoffend non-sexually than sexually

Siria, S., Echeburúa, E., \& Amor, P. J. (in press). Adolescents Adjudicated for Sexual Offending: Differences Between Sexual Reoffenders and Sexual Non-Reoffenders. Journal of Interpersonal Violence. https://doi.org/10.1177/08862605211015209 
(Caldwell, 2010; Kettrey \& Lipsey, 2018; Newman et al., 2019). Prospective studies have evidenced that juvenile sex offending is limited to the adolescence stage and only a very small group will persist into adulthood (Christiansen \& Vincent, 2013; Lussier \& Blokland, 2014; Lussier et al., 2012). However, the concept and the measurement of sexual recidivism has some implications that should be emphasized.

\section{The Definition of Recidivism}

The definition of general and sexual recidivism across the existing investigations usually relies on its legal concept. Researchers frequently use official records to quantify rates of recidivism, although different official data, such as arrests, charges, and convictions, can be found throughout different studies (Mallie et al., 2011). Moreover, recidivism is usually assessed after follow-up periods, ranging from some months to several years (Caldwell, 2016). Consequently, depending on the follow-up interval, sexual recidivism is measured, in some cases, when ASO are still in their adolescence while other findings are related to adult sexual reoffending. In any case, the vast majority of recent research on ASO reveals rates of sexual recidivism below $10 \%$ (Caldwell, 2016; Cale et al., 2016; Calleja, 2015; Christiansen \& Vincent, 2013; Fanniff et al., 2017; Newman et al., 2019; Ozkan et al., 2020).

However, due to the particularities of the sexual violence, the age of the offenders, and the characteristics of some of their victims (e.g., children, familyrelated), some of these offenses go unreported to authorities (Abbey, 2005).

Consequently, the use of official records to quantify sexual recidivism (i.e., new criminal offenses) usually leads to underestimating the actual rates of the repetition of this behavior, which can be relatively stable during adolescence (Caldwell, 2010). The

Siria, S., Echeburúa, E., \& Amor, P. J. (in press). Adolescents Adjudicated for Sexual Offending: Differences Between Sexual Reoffenders and Sexual Non-Reoffenders. Journal of Interpersonal Violence. https://doi.org/10.1177/08862605211015209 
majority of youth who engage in sexually coercive behavior are never officially detected (Caldwell, 2007), and some of those who are detected and classified as first offenders using official reports could be undetected sexual reoffenders (Worling \& Curwen, 2000).

For these reasons, it is important to measure not only official records of recidivism, but also the information from professionals and adolescents' self-reported data on undetected events of sexual violence. This would provide a more accurate approach to the rates of sexually coercive behaviors committed by ASO over the time leading up to their adjudication. This proposed conceptualization does not conflict with the legal assessment of recidivism and may provide complementary and encouraging findings.

\section{Risk Factors Related to Sexual Recidivism}

Some authors have concluded that the risk factors that contribute to the commission of a first sexual offense might differ from the risk factors that lead to sexual reoffending (Mallie et al., 2011; McCann \& Lussier, 2008; Ozkan et al., 2020). There are some empirically supported risk factors for sexual reoffending in ASO. The most strongly evidenced are those related to the presence of deviant sexual interests (towards children or violence), prior legal sanctions for sexual offenses, sexual offending against two or more victims, sexual offenses against stranger victims, and social isolation (Fanniff et al., 2017; Worling \& Langstrom, 2006). Moreover, evidence about other variables that might predict sexual recidivism, such as deviant sexual fantasies with children (Worling \& Curwen, 2000), having been sexually victimized during childhood (Mallie et al., 2011), having deviant sexual experiences (Kenny et al., 2001), lack of

Siria, S., Echeburúa, E., \& Amor, P. J. (in press). Adolescents Adjudicated for Sexual Offending: Differences Between Sexual Reoffenders and Sexual Non-Reoffenders. Journal of Interpersonal Violence. https://doi.org/10.1177/08862605211015209 
school attendance, previous non-sexual offenses, and sexual offending against children (Christiansen \& Vincent, 2013) has been found.

However, this evidence has resulted from research that assessed risk factors related to officially detected sexual recidivism. Following the previously presented nuances about the assessment of undetected events of sexual violence, it may be informative clinically and in terms of risk management to identify the risk factors that are present among those ASO who have repeated undetected sexually coercive behaviors before their contact with the juvenile justice system and among those who have committed only one sexual offense. This might also be useful to understand differential sexual offending trajectories (Cale et al., 2016).

\section{Purpose of the Present Study}

Numerous investigations have been focused on ASO recidivism risk, the majority of them attempting to identify the risk factors that have led to sexual reoffending after a period of time. However, there is a research gap in the classification of ASO according to whether or not they have repeated undetected sexually coercive behaviors before their adjudication. An analysis of adjudicated and non-adjudicated sexually coercive behaviors is important for a more comprehensive understanding of ASO (Riser et al., 2013). Thus, the identification in the present study of the sexual offenses that have not been officially reported or convicted might reveal a more accurate description of this sample of ASO.

The main aims of this study were, first, to determine the prevalence rate of undetected sexually coercive behaviors among a sample of adjudicated ASO. This would allow distinguishing those ASO who have been engaged in different events of

Siria, S., Echeburúa, E., \& Amor, P. J. (in press). Adolescents Adjudicated for Sexual Offending: Differences Between Sexual Reoffenders and Sexual Non-Reoffenders. Journal of Interpersonal Violence. https://doi.org/10.1177/08862605211015209 
sexually coercive behavior before their official detection (even if not adjudicated for all of them) from those who have committed a single sexual offense (which led to their adjudication). The second aim was to compare ASO subgroups—-sexual reoffenders (SR) and sexual non-reoffenders (SNR) - to examine whether differential characteristics and risk factors may be associated with each group (with particular focus on sexual development-related variables). By improving the knowledge of the characteristics of SR and SNR, differential treatment needs can be identified by which to develop more tailored treatment programs.

\section{Method}

\section{Participants}

The sample consisted of 73 male ASO between 14 and 18 years of age $(M=$ $15.68, S D=1.12$ ) who were serving a sentence after committing a sexual offense. According to the Spanish law, sexual offenses were as follows: sexual aggression-with violence or intimidation — $(58.2 \%)$, sexual abuse — without violence or intimidation and without victim's consent - $(36.3 \%)$, child pornography $(2.2 \%)$, exhibitionism $(1.1 \%)$, sexual harassment $(1.1 \%)$, and prostitution and corruption of minors $(1.1 \%)$. The sample was gathered in various Spanish cities from custodial facilities $(72.6 \%)$ as well as from community-based programs (27.4\%). Of the total sample, 43 participants $(59 \%)$ were Spanish, and 30 (41\%) were of non-Spanish origin.

Sample inclusion criteria were (a) being sentenced for committing a sexual offense between 14 and 18 years of age, (b) voluntarily participating in the study, and (c) having the capacity to read and understand Spanish.

Siria, S., Echeburúa, E., \& Amor, P. J. (in press). Adolescents Adjudicated for Sexual Offending: Differences Between Sexual Reoffenders and Sexual Non-Reoffenders. Journal of Interpersonal Violence. https://doi.org/10.1177/08862605211015209 
The initial sample was composed of 102 ASO but 29 of them (28.4\%) refused to participate. The participants were divided into two groups depending on the number of different events of coercive sexual behavior that they had committed before their adjudication, although not all of these episodes were officially reported. To identify how many times the ASO had performed such behavior, information was collected from official files, self-reports, and the professionals in charge.

Thus, the participants were assigned to the SR group when they had committed more than one event of sexually coercive behavior $(n=34)$. The criteria for including the participants in this group were (a) committing various events of sexually coercive behavior at different time points towards the same victim and/or (b) committing one event of sexually coercive behavior at different time points towards different victims. None of the participants committed a sexual offense towards two or more victims at the same time, so this was not evaluated. On the other hand, the group of SNR was composed of those ASO who had committed a single event of coercive sexual behavior for which they were adjudicated $(n=39)$. Taking into account these criteria, some participants could have only one sexual offense on their official criminal records but still be considered as SR because they had previously committed more than one event of sexually coercive behavior.

\section{Assessment Measures}

\section{Coding Manual}

A coding manual was created to collect information from multiple sources. The major categories and variables contained are described below.

Siria, S., Echeburúa, E., \& Amor, P. J. (in press). Adolescents Adjudicated for Sexual Offending: Differences Between Sexual Reoffenders and Sexual Non-Reoffenders. Journal of Interpersonal Violence. https://doi.org/10.1177/08862605211015209 
Family characteristics. Parental marital status, separation from parents during childhood (if an interruption to the relationship between the ASO and one or both parents during childhood occurred for a period of at least 4 months under circumstances of family conflict, death, abandonment, or events such as parents' imprisonment, hospitalization, or child institutionalization), maltreatment history (physical violence, emotional violence, sexual violence, and/or neglect by a family member), exposure to violence towards women, living in a dysfunctional household (if the presence of one or more of the following was detected: home instability, many and different people living with the family, habitual changes of caregivers, non-stable adult figures, and habitual family conflict), and Child Welfare System involvement.

School progress. School absenteeism and/or dropout, school year repetition (once or more), disruptive behavior at school (violent and nonviolent towards teachers and/or classmates), and the presence of bullying (perpetrated or suffered) at school.

Psychiatric history and substance use. Previous psychiatric diagnosis, regular substance consumption (drugs and alcohol), and age at the onset of substance consumption. Interpersonal relationships and sexual conduct. Engagement in antisocial behavior with his group of friends, age at first consensual sexual intercourse, consensual sexual intercourse before committing the sexual crime, partner relationship before the sexual crime, and having a partner when committing the sexual crime.

Sexual development-related variables. Sexually victimized during childhood, early consensual sexual intercourse with a similar-age partner (before age 13), exposure to inappropriate sexual behavior in the family environment during childhood, beginning of

Siria, S., Echeburúa, E., \& Amor, P. J. (in press). Adolescents Adjudicated for Sexual Offending: Differences Between Sexual Reoffenders and Sexual Non-Reoffenders. Journal of Interpersonal Violence. https://doi.org/10.1177/08862605211015209 
pornography consumption at an early age (before age 12), and the presence of deviant sexual fantasies (with violence or with children at least 4 years younger).

Sexual offense characteristics. Age at first sexual crime, type of offense (according to Spanish law), use of physical violence during the offense (instrumental or expressive), crime planning (planned or impulsive), place of commission (public, private, or Internet), and number of offenders (individual or group).

Victim characteristics. Victim's age (child [the victim was at least 4 years younger than offender], peer [up to 4 years younger or older], or adult [the victim was more than 4 years older than the offender]), victim's gender (male or female), previous relationship (family, acquaintance, or stranger).

Criminal history information. Obtained from official criminal records, from juveniles' self-report, and the interviews with the professionals in charge. Previous sexual and nonsexual offenses were coded both when they were officially reported or when, without official records, additional episodes of sexually coercive behaviors were selfreported by the ASO or informed by the professionals in charge.

\section{Empathy Self-Report}

The Interpersonal Reactivity Index (IRI) (Davis, 1980; Spanish version of PérezAlbéniz et al., 2003) is a 28-item self-report instrument that measures empathy from a multidimensional perspective, which includes emotional and cognitive components. It comprises four subscales: Perspective Taking (PT), Fantasy (FS), Empathic Concern (EC), and Personal Distress (PD). Each subscale contains 7 items scored using a 5-point Likert scale, ranging from 0 (does not describe me well) to 4 (describes me very well). Scores on each scale can range from 0 to 28 , with lower scores indicating lower levels

Siria, S., Echeburúa, E., \& Amor, P. J. (in press). Adolescents Adjudicated for Sexual Offending: Differences Between Sexual Reoffenders and Sexual Non-Reoffenders. Journal of Interpersonal Violence. https://doi.org/10.1177/08862605211015209 
of empathy. The combination of the PT and FS scales assesses cognitive aspects, while the EC and PD scales evaluate the emotional reaction. The Spanish adaptation revealed internal consistency with alpha coefficients ranging from .67 to .80 (Pérez-Albéniz et al., 2003).

\section{Procedure}

An ex post facto research design was used to compare two groups of ASO (SR and SNR) and to explore the risk factors, sexual crime characteristics, and empathy.

All of the 17 Spanish Juvenile Justice System authorities from each Autonomous Region were asked to participate in the study. Of the total number of authorities, seven gave permission to conduct the study and signed a collaboration agreement. Ethical approval for the data collection was obtained separately through the seven Juvenile Justice System authorities. Prior to inclusion in the study, informed consent was obtained from juveniles over 18 years old, and from juveniles' parents or legal guardians when they were under the age of 18.

Once the sample was selected using the previously described criteria, data collection was carried out. The first author used three different sources to collect data over three sessions: (a) a review of the individual case files, (b) an individual interview with the professionals in charge (psychologists and social workers), and (c) an individual semi-structured interview and the administration of the IRI self-report with each ASO. Data gathering took place from January 2013 to December 2015.

\section{Data Analysis}

Descriptive analyses were conducted for all variables. The intergroup differences between SR and SNR were analyzed using the chi-square $\left(\chi^{2}\right)$ test (Yates'

Siria, S., Echeburúa, E., \& Amor, P. J. (in press). Adolescents Adjudicated for Sexual Offending: Differences Between Sexual Reoffenders and Sexual Non-Reoffenders. Journal of Interpersonal Violence. https://doi.org/10.1177/08862605211015209 
correction for continuity was used when expected frequencies were smaller than 5) or Student's $t$ test, depending on the type of the variables. The effect sizes (ES) were estimated through the Phi coefficient ( $\Phi$; for 2 x 2 contingency tables), Cramer's $V$, and Cohen's $d$. Effect sizes for Phi, $V$, and $d$ were interpreted as follows: $0.10-0.29$ (small), $0.30-0.49$ (medium), and $\geq 0.50$ (large) (Cohen, 1988). When variables reached statistically significant differences between groups, Odds Ratio $(O R)$ was used. $O R$ allows comparing the relative odds of the occurrence of an outcome (belonging to SR or SNR group), given exposure to the variable of interest. The interpretation of $O R$ was as follows: $O R=1$ means that exposure does not affect odds of outcome, $O R>1$ means that exposure is associated with higher odds of outcome, and $O R<1$ means that exposure is associated with lower odds of outcome (Szumilas, 2010). A difference of $p$ $<.05$ was considered significant. All the statistical analyses were carried out using SPSS 25.0.

\section{Results}

The prevalence rate of ASO who engaged in repetitive sexually coercive behaviors before their adjudication was $46.58 \%(n=34)$. The mean age of SR $(M=$ $15.38, S D=1.10)$ and SNR $(M=15.72, S D=1.17)$ at the time of the adjudicated sexual offense did not reach significant differences $(p=.207)$. Additionally, no significant differences between groups in terms of nationality were found $(p=.823)$.

Table 1 shows that no significant group differences were found in the familycharacteristics-related variables. Most ASO, both SR and SNR, lived in dysfunctional households, lived separated from their parents at some point of their childhood, and were victims of different types of intrafamily maltreatment.

Siria, S., Echeburúa, E., \& Amor, P. J. (in press). Adolescents Adjudicated for Sexual Offending: Differences Between Sexual Reoffenders and Sexual Non-Reoffenders. Journal of Interpersonal Violence. https://doi.org/10.1177/08862605211015209 


\section{INSERT HERE TABLE 1}

Regarding school background, as shown in Table 2, the variables that reached significant differences were those related to the presence of bullying. SR were more likely to have been victims of bullying $(O R=3)$, and SNR had more prevalence of bullying perpetration $(O R=3.25)$.

Additionally, SNR reported significantly higher rates of antisocial conduct committed with their group of friends than did SR $(O R=4.22)$. No significant differences were found in the diagnoses of a psychiatric condition or substance consumption (Table 2).

\section{INSERT HERE TABLE 2}

The vast majority of the adolescents had had one or more partner relationships before the adjudicated sexual offense, with no significant differences between groups. However, SNR had a significantly higher percentage of consensual sexual intercourse prior to the commission of the sexual offense $(O R=8.40)$ and of having a partner when they committed the sexual crime $(O R=3.25)$ than did SR (Table 3).

Results showed that some of the variables related to sexual development were significantly different between groups. SR reported significantly higher rates of a sexualized family environment $(O R=6.91)$, sexual victimization during childhood $(O R$ $=12.95)$, and deviant sexual fantasies $(44 \%$ vs. $0 \%)$. On the other hand, SNR had significantly higher rates of early consensual sexual intercourse before age $13(O R=$ 3.59) (Table 3).

\section{INSERT HERE TABLE 3}

Siria, S., Echeburúa, E., \& Amor, P. J. (in press). Adolescents Adjudicated for Sexual Offending: Differences Between Sexual Reoffenders and Sexual Non-Reoffenders. Journal of Interpersonal Violence. https://doi.org/10.1177/08862605211015209 
Table 4 presents the offense-characteristics-related variables. As can be seen, SR presented a significantly higher percentage of sex-only offenders (they committed only sexual offenses $)(O R=2.86)$. Meanwhile, SNR were sex-plus offenders (they committed both sexual and nonsexual offenses) in a significantly higher percentage.

Regarding the characteristics of the sexual offenses, significant differences were found between groups. SR were more likely to have committed the sexual offenses alone $(O R=7.98)$, previously premeditated $(O R=29.17)$, towards a child $(O R=6.80)$, and toward family-related victims $(O R=6.82)$. On the other hand, SNR were more likely to have committed the sexual offense in group, impulsively, and towards a peer or adult victim. Half of the sample used physical violence against the victim, most of it instrumental, with no significant differences between groups. Finally, no significant differences were found regarding the victim's gender and the place of commission of the sexual offense.

\section{INSERT HERE TABLE 4}

The scores of the IRI questionnaire revealed no significant differences in the level of empathy between groups (Table 5).

\section{INSERT HERE TABLE 5}

\section{Discussion}

The findings obtained in this study showed that the classification of ASO in terms of the repetition of sexually coercive behaviors before their adjudication has a promising utility because several differences between SR and SNR groups have been found. Moreover, the use of this conceptualization and the measurement of the sexually coercive events rate throughout professionals' information and participants' self-report seems to

Siria, S., Echeburúa, E., \& Amor, P. J. (in press). Adolescents Adjudicated for Sexual Offending: Differences Between Sexual Reoffenders and Sexual Non-Reoffenders. Journal of Interpersonal Violence. https://doi.org/10.1177/08862605211015209 
yield a more accurate interpretation of the dynamics of sexual violence of ASO than the merely legal concept of recidivism. The findings of this study are not comparable with those studies that rely on official recidivism. Thus, the most relevant differences between groups will be discussed below.

Current results indicate that ASO who have repeatedly engaged in sexually coercive behaviors towards the same or different victims before their adjudication constitute nearly the half of the sample (46.58\%). No direct comparisons can be drawn between this rate and those from previous research that measures official sexual recidivism (Caldwell, 2016; Fanniff et al., 2017; Kettrey \& Lipsey, 2018). However, it might be argued that studies that exclusively use official records of recidivism fail to capture the actual rates of sexual offenses during adolescence (Caldwell, 2010).

Comparisons between SR and SNR revealed many significant and encouraging findings. Family background-related variables did not show differences between groups. Rates of childhood maltreatment, separation from parents, or living in a dysfunctional household are highly prevalent in all ASO of the sample. This finding supports that such adverse experiences during childhood are related to most of the adolescents who sexually offend (Dillard \& Beaujolais, 2019; Siria et al., 2020).

Regarding academic context, most of the participants repeated one or more school years, presented school absenteeism, and performed disruptive behavior at school. In this study, these variables are not significantly more prevalent among the SR group, so they might be characteristics common to all ASO. It can be reasoned that the adverse household environments in which most ASO have grown up may have had detrimental effects on their learning process and their conduct at school (Kenny et al.,

Siria, S., Echeburúa, E., \& Amor, P. J. (in press). Adolescents Adjudicated for Sexual Offending: Differences Between Sexual Reoffenders and Sexual Non-Reoffenders. Journal of Interpersonal Violence. https://doi.org/10.1177/08862605211015209 
2001; Seto \& Lalumiere, 2010). What should be pointed out-with caution because of the small effect sizes - is that SR had 3 times the odds of being victims of bullying and SNR had 3.25 times the odds of being a bullying perpetrator. Because of their relevance, further research with ASO should more precisely consider school behavior and academic outcomes.

The sexual development is an essential aspect to consider when ASO are assessed (Goulet \& Tardif, 2018; Seto \& Lalumiere, 2010; Siria et al., 2020). Current findings showed remarkable differences between groups in the participants' sexual behavior and sexualization process. First, SNR had 8 times the odds of having had consensual sexual intercourse before committing the sexual offense. A key point is that $41 \%$ of SNR stated that they were in a relationship when they committed the sexual offense but none of these offenses were committed against their partner. This rate was significantly higher, although with a small effect size, than in the SR group. On the other hand, sexual victimization during childhood, living in a sexually inadequate family environment during childhood, and, especially, the presence of deviant sexual fantasies - which are exclusively present in the group of SR - were significantly higher in the SR group with medium-large effect sizes. These results might be partially related to those of Burton et al. (2011), who found that sexual victimization among ASO was linked to early exposure to pornography and deviant sexual arousal. Grabell and Knight (2009) found, in a sample of ASO, that sexual victimization during childhood and deviant sexual fantasies were linked and moderated by the age at which the abuse occurred. Nevertheless, more research with larger samples of ASO is needed to further assess this relationship. SR had significantly more inappropriate and violent sexual experiences during childhood that

Siria, S., Echeburúa, E., \& Amor, P. J. (in press). Adolescents Adjudicated for Sexual Offending: Differences Between Sexual Reoffenders and Sexual Non-Reoffenders. Journal of Interpersonal Violence. https://doi.org/10.1177/08862605211015209 
might have affected their sexual development. These experiences should be further evaluated along with additional risk factors to analyze their effects on the initial development of adolescent sexually coercive behavior (Fox et al., 2015), and on the repetition of sexual violence events during adolescence.

Some offense characteristics also showed significant differences between groups. SR were more likely to be sex-only offenders, to plan the offense, and to commit sexual offenses alone against a child family victim. Conversely, SNR had a significantly higher number of additional non-sexual offenses (i.e., sex-plus offenders), committed the sexual offenses more often in group, without planning, and against peer or adult victims. In relation to the above, the fact that SNR had 4 times the odds of engaging in antisocial conduct with their group of friends may lead to expect that this group is engaged in a broader range of antisocial behavior than the SR group. It is important to note that there were no significant differences in age between the groups when they were adjudicated. Hence, SNR did not have more time to commit additional offenses. In line with Kettrey and Lipsey (2018), it is important to take into account these findings to interpret the differential offending trajectories of each group of ASO.

Regarding levels of empathy, no significant differences were found between SR and SNR. Moreover, both groups' scores were similar or slightly higher than normative samples of adolescents in Spain (Mestre-Escrivá et al., 2004). In line with Varker et al. (2008), these results support that ASO, whether one timers or repetitive, do not appear to have general empathy deficits. The IRI assesses general empathy but not specific empathy. Therefore, future research should examine if ASO have victim-specific empathy deficits (Varker et al., 2008).

Siria, S., Echeburúa, E., \& Amor, P. J. (in press). Adolescents Adjudicated for Sexual Offending: Differences Between Sexual Reoffenders and Sexual Non-Reoffenders. Journal of Interpersonal Violence. https://doi.org/10.1177/08862605211015209 
In summary, the conclusion that can be drawn is that, although the dysfunctional and violent family background is similar for all ASO of the sample, two behavioral pathways differentiate SR from SNR. The SR group showed a more socially inhibited behavior and a higher negative impact on their sexual development that has led to a more sexually deviant conduct (e.g., deviant sexual fantasies, child victims, family victims, planning the sexual offense, and the commission of the sex offenses by himself). These characteristics are consistent with Seto and Lalumiere's (2010) special explanations for adolescent sexual offending. On the other hand, the SNR group showed a greater involvement with peers socially and sexually during adolescence, they appeared to associate with delinquent peers, and they exhibited generalized patterns of antisocial behavior (e.g., bullying perpetrators, nonsexual criminal offending, sexually precocious) that also happened to include the sexual offense. This presentation appears to reflect the effect of developing antisocial personality traits, antisocial beliefs and attitudes, and influences of antisocial peers consistent with the general delinquency explanation for adolescent sexual offending (Seto \& Lalumiere, 2010).

\section{Limitations}

Several limitations need to be taken into consideration in this study. The limited size of the sample has to be taken into account when interpreting the results and does not allow generalizing the results. This research can be considered a first step in the comparison of SR and SNR, but further research with larger samples is needed. Second, the sample was obtained exclusively from adjudicated ASO who were serving a sentence due to the severity of the committed sexual offense. Hence, results may not be generalizable to all the young people who commit less severe sexually coercive

Siria, S., Echeburúa, E., \& Amor, P. J. (in press). Adolescents Adjudicated for Sexual Offending: Differences Between Sexual Reoffenders and Sexual Non-Reoffenders. Journal of Interpersonal Violence. https://doi.org/10.1177/08862605211015209 
behaviors. Third, the use of a retrospective design may have biased or underreported important information, and no causal links between risk factors and the repetition of sexually coercive behaviors can be concluded. Despite the use of multiple information sources to identify previous sexual offenses, some of the participants may have committed more events of sexual violence than those that were recorded. However, these missing data are intrinsic in any research study. Finally, it was not possible to assess long-term recidivism, which would have allowed making comparisons with previous studies and would have led to drawing more accurate conclusions.

Issues of diversity are limited to sex and age in this study. Participants were all adolescent males, which can lead to generalizing the results with caution to similar samples, but not to female perpetrators or different-aged samples. Although we obtained information about nationality, we did not differentiate the sample according to this variable because no significant differences between SR and SNR groups were found in this variable. Finally, this is one of the first studies with an ASO sample carried out in Spain, which makes it possible to compare the results internationally with this region. Nonetheless, it would be interesting to further investigate whether nationality, culture, and other diversity-related issues allow to differentiate the characteristics of ASO.

\section{Conclusion and Implications}

This study demonstrates the relevance of examining the classification between ASO who have repeatedly committed sexually coercive behaviors before their adjudication and those who have engaged in this behavior only once because several significant differences have been addressed. Empirical data have been provided to better understand the characteristics of this sample of ASO and the two possible behavioral

Siria, S., Echeburúa, E., \& Amor, P. J. (in press). Adolescents Adjudicated for Sexual Offending: Differences Between Sexual Reoffenders and Sexual Non-Reoffenders. Journal of Interpersonal Violence. https://doi.org/10.1177/08862605211015209 
pathways. As the heterogeneity of ASO has been well established (Cale et al., 2016; Newman et al., 2019), current findings suggest that the distinction between SR and SNR constitutes an emerging research focus for validating this classification with larger samples. It would help to identify differential treatment needs and provide relevant information to adapt intervention and prevention efforts to each subtype to enhance treatment outcomes (Fox \& DeLisi, 2018; Newman et al., 2019).

Taking into consideration the presence of specific risk factors in each ASO would benefit court decisions, the application of multidisciplinary treatment designs, and the monitoring upon release (Newman et al., 2019; Prisco, 2015; Riser et al., 2013; Yoder et al., 2016). Given the common historical background of these juveniles, the final aim of specialized interventions should not be interpreted from a reductionist perspective of diminishing long-term sexual recidivism. Due to the behavior changesincluding psychosexual behavior-during adolescence, risk assessments should be applied in short-term outcomes (Fanniff et al., 2017; Riser et al., 2013). Finally, these interventions might essentially reinforce the youths' protective factors and individual capacities to minimize the consequences of harm suffered during childhood and to reintegrate them familiarly and socially.

Siria, S., Echeburúa, E., \& Amor, P. J. (in press). Adolescents Adjudicated for Sexual Offending: Differences Between Sexual Reoffenders and Sexual Non-Reoffenders. Journal of Interpersonal Violence. https://doi.org/10.1177/08862605211015209 


\section{References}

Abbey, A. (2005). Lessons learned and unanswered questions about sexual assault perpetration. Journal of Interpersonal Violence, 20(1), 39-42. https://doi.org/10.1177/0886260504268117

Burton, D. L., Duty, K. J., \& Leibowitz, G. S. (2011). Differences between sexually victimized and nonsexually victimized male adolescent sexual abusers: Developmental antecedents and behavioral comparisons. Journal of Child Sexual Abuse, 20(1), 77-93. https://doi.org/10.1080/10538712.2011.541010

Butler, S. M., \& Seto, M. C. (2002). Distinguishing two types of adolescent sex offenders. Journal of the American Academy of Child and Adolescent Psychiatry, 41(1), 83-90. https://doi.org/10.1097/00004583-200201000-00015

Caldwell, M. F. (2007). Sexual offense adjudication and sexual recidivism among juvenile offenders. Sexual Abuse, 19(2), 107-113. https://doi.org/10.1007/s11194-007-9042-7

Caldwell, M. F. (2010). Study characteristics and recidivism base rates in juvenile sex offender recidivism. International Journal of Offender Therapy and Comparative Criminology, 54(2), 197-212. https://doi.org/10.1177/0306624x08330016

Caldwell, M. F. (2016). Quantifying the decline in juvenile sexual recidivism rates. Psychology Public Policy and Law, 22(4), 414-426. https://doi.org/10.1037/law0000094

Cale, J., Smallbone, S., Rayment-McHugh, S., \& Dowling, C. (2016). Offense trajectories, the unfolding of sexual and non-sexual criminal activity, and sex offense characteristics of adolescent sex offenders. Sexual Abuse, 28(6), 791812. https://doi.org/10.1177/1079063215580968

Calleja, N. G. (2015). Juvenile sex and non-sex offenders: A comparison of recidivism and risk. Journal of Addictions \& Offender Counseling, 36(1), 2-12. https://doi.org/10.1002/j.2161-1874.2015.00031.x

Christiansen, A. K., \& Vincent, J. P. (2013). Characterization and prediction of sexual and nonsexual recidivism among adjudicated juvenile sex offenders. Behavioral Sciences \& the Law, 31(4), 506-529. https://doi.org/10.1002/bsl.2070

Cohen, J. (1988). Statistical power analysis for the behavioral sciences. Lawrence Erlbaum Associates.

Davis, M. H. (1980). A multidimensional approach to individual differences in empathy Catalog of Selected Documents in Psychology, 10, 1-19.

Dillard, R., \& Beaujolais, B. (2019). Trauma and adolescents who engage in sexually abusive behavior: A review of the literature. Journal of Child Sexual Abuse, 28(6), 629-648. https://doi.org/10.1080/10538712.2019.1598528

Fanniff, A. M., Schubert, C. A., Mulvey, E. P., Iselin, A. M. R., \& Piquero, A. R. (2017). Risk and outcomes: Are adolescents charged with sex offenses different from other adolescent offenders? Journal of Youth and Adolescence, 46(7), 1394-1423. https://doi.org/10.1007/s10964-016-0536-9

Fox, B., \& DeLisi, M. (2018). From criminological heterogeneity to coherent classes: Developing a typology of juvenile sex offenders. Youth Violence and Juvenile Justice, 16(3), 299-318. https://doi.org/10.1177/1541204017699257

Siria, S., Echeburúa, E., \& Amor, P. J. (in press). Adolescents Adjudicated for Sexual Offending: Differences Between Sexual Reoffenders and Sexual Non-Reoffenders. Journal of Interpersonal Violence. https://doi.org/10.1177/08862605211015209 
Fox, B. H., Perez, N., Cass, E., Baglivio, M. T., \& Epps, N. (2015). Trauma changes everything: Examining the relationship between adverse childhood experiences and serious, violent and chronic juvenile offenders. Child Abuse \& Neglect, 46, 163-173. https://doi.org/10.1016/j.chiabu.2015.01.011

Goulet, J. A. S., \& Tardif, M. (2018). Exploring sexuality profiles of adolescents who have engaged in sexual abuse and their link to delinquency and offense characteristics. Child Abuse \& Neglect, 82, 112-123. https://doi.org/10.1016/j.chiabu.2018.05.023

Grabell, A. S., \& Knight, R. A. (2009). Examining childhood abuse patterns and sensitive periods in juvenile sexual offenders. Sexual Abuse, 21(2), 208-222. https://doi.org/10.1177/1079063209333133

Hart-Kerkhoffs, L. A., Doreleijers, T. A. H., Jansen, L. M. C., van Wijk, A. P. H., \& Bullens, R. A. R. (2009). Offense related characteristics and psychosexual development of juvenile sex offenders. Child and Adolescent Psychiatry and Mental Health, 3(1), 19-28. https://doi.org/10.1186/1753-2000-3-19

Keelan, C. M., \& Fremouw, W. J. (2013). Child versus peer/adult offenders: A critical review of the juvenile sex offender literature. Aggression and Violent Behavior, 18(6), 732-744. https://doi.org/10.1016/j.avb.2013.07.026

Kemper, T. S., \& Kistner, J. A. (2010). An evaluation of classification criteria for juvenile sex offenders. Sexual Abuse, 22(2), 172-190. https://doi.org/10.1177/1079063210366270

Kenny, D. T., Keogh, T., \& Seidler, K. (2001). Predictors of recidivism in Australian juvenile sex offenders: Implications for treatment. Sexual Abuse, 13(2), 131-148. https://doi.org/10.1177/107906320101300206

Kettrey, H. H., \& Lipsey, M. W. (2018). The effects of specialized treatment on the recidivism of juvenile sex offenders: A systematic review and meta-analysis. Journal of Experimental Criminology, 14(3), 361-387. https://doi.org/10.1007/s11292-018-9329-3

Kjellgren, C., Wassberg, A., Carlberg, M., Langstrom, N., \& Svedin, C. G. (2006). Adolescent sexual offenders: A total survey of referrals to social services in Sweden and subgroup characteristics. Sexual Abuse, 18(4), 357-372. https://doi.org/10.1007/s11194-006-9026-Z

Lillard, C. M., Cooper-Lehki, C., Fremouw, W. J., \& DiSciullo, V. A. (2020). Differences in psychosexual development among child, peer, and mixed juvenile sex offenders. Journal of Forensic Sciences, 65(2), 526-534. https://doi.org/10.1111/1556-4029.14194

Lussier, P., \& Blokland, A. (2014). The adolescence-adulthood transition and Robins's continuity paradox: Criminal career patterns of juvenile and adult sex offenders in a prospective longitudinal birth cohort study. Journal of Criminal Justice, 42(2), 153-163. https://doi.org/10.1016/j.jcrimjus.2013.07.004

Lussier, P., Van Den Berg, C., Bijleveld, C., \& Hendriks, J. (2012). A developmental taxonomy of juvenile sex offenders for theory, research, and prevention: The adolescent-limited and the high-rate slow desister. Criminal Justice and Behavior, 39(12), 1559-1581. https://doi.org/10.1177/0093854812455739

Siria, S., Echeburúa, E., \& Amor, P. J. (in press). Adolescents Adjudicated for Sexual Offending: Differences Between Sexual Reoffenders and Sexual Non-Reoffenders. Journal of Interpersonal Violence. https://doi.org/10.1177/08862605211015209 
Mallie, A. L., Viljoen, J. L., Mordell, S., Spice, A., \& Roesch, R. (2011). Childhood abuse and adolescent sexual re-offending: A meta-analysis. Child and Youth Care Forum, 40, 401-417. https://doi.org/10.1007/s10566-010-9136-0

McCann, K., \& Lussier, P. (2008). Antisociality, sexual deviance, and sexual reoffending in juvenile sex offenders. A meta-analytical investigation. Youth Violence and Juvenile Justice, 6(4), 363-385. https://doi.org/10.1177/1541204008320260

Mestre-Escrivá, V., Frías-Navarro, D., \& Samper-García, P. (2004). Measuring empathy: The Interpersonal Reactivity Index. Psicothema, 16(2), 255-260.

Newman, J. L. E., Larsen, J. L., Thompson, K., Cyperski, M., \& Burkhart, B. R. (2019). Heterogeneity in male adolescents with illegal sexual behavior: A latent profile approach to classification. Sexual Abuse, 31(7), 789-811. https://doi.org/10.1177/1079063218784554

Oxnam, P., \& Vess, J. (2008). A typology of adolescent sexual offenders: Millon Adolescent Clinical Inventory profiles, developmental factors, and offence characteristics. Journal of Forensic Psychiatry \& Psychology, 19(2), 228-242. https://doi.org/10.1080/14789940701694452

Ozkan, T., Clipper, S. J., Piquero, A. R., Baglivio, M., \& Wolff, K. (2020). Predicting sexual recidivism. Sexual Abuse, 32(4), 375-399. https://doi.org/10.1177/1079063219852944

Prisco, R. (2015). Parental involvement in juvenile sex offender treatment: Requiring a role as informed supervisor. Family Court Review, 53(3), 487-503. https://doi.org/10.1111/fcre.12169

Pérez-Albéniz, A., de Paúl, J., Etxeberria, J., Montes, M. P., \& Torres, E. (2003). Spanish adaptation of the Interpersonal Reactivity Index. Psicothema, 15(2), 267-272.

Rajlic, G., \& Gretton, H. M. (2010). An examination of two sexual recidivism risk measures in adolescent offenders: The moderating effect of offender type. Criminal Justice and Behavior, 37(10), 1066-1085. https://doi.org/10.1177/0093854810376354

Riser, D. K., Pegram, S. E., \& Farley, J. P. (2013). Adolescent and young adult male sex offenders: Understanding the role of recidivism. Journal of Child Sexual Abuse, 22(1), 9-31. https://doi.org/10.1080/10538712.2013.735355

Seto, M. C., \& Lalumiere, M. L. (2010). What is so special about male adolescent sexual offending? A review and test of explanations through meta-analysis. Psychological Bulletin, 136(4), 526-575. https://doi.org/10.1037/a0019700

Siria, S., Echeburúa, E., \& Amor, P. J. (2020). Characteristics and risk factors in juvenile sexual offenders. Psicothema, 32(3), 314-321. https://doi.org/10.7334/psicothema2019.349

Szumilas, M. (2010). Explaining odds ratios. Journal of the Canadian Academy of Child and Adolescent Psychiatry, 19(3), 227-229.

Varker, T., Devilly, G. J., Ward, T., \& Beech, A. R. (2008). Empathy and adolescent sexual offenders: A review of the literature. Aggression and Violent Behavior, 13(4), 251-260. https://doi.org/10.1016/j.avb.2008.03.006

Siria, S., Echeburúa, E., \& Amor, P. J. (in press). Adolescents Adjudicated for Sexual Offending: Differences Between Sexual Reoffenders and Sexual Non-Reoffenders. Journal of Interpersonal Violence. https://doi.org/10.1177/08862605211015209 
Worling, J. R., \& Curwen, T. (2000). Adolescent sexual offender recidivism: Success of specialized treatment and implications for risk prediction. Child Abuse \& Neglect, 24(7), 965-982. https://doi.org/10.1016/s0145-2134(00)00147-2

Worling, J. R., \& Langstrom, N. (2006). Risk of sexual recidivism in adolescents who offend sexually: Correlates and assessment. In H. E. Barbaree \& W. L. Marshall (Eds.), The juvenile sex offender (pp. 219-247). The Guilford Press.

Yoder, J. R., Ruch, D., \& Hodge, A. (2016). Families of youth who have sexually offended: Understanding shared experiences and moving towards a typology. Journal of Child and Family Studies, 25(5), 1581-1593. https://doi.org/10.1007/s10826-015-0339-8

Zeng, G., Chu, C. M., Koh, L. L., \& Teoh, J. (2015). Risk and criminogenic needs of youth who sexually offended in Singapore: An examination of two typologies. Sexual Abuse, 27(5), 479-495. https://doi.org/10.1177/1079063213520044

Siria, S., Echeburúa, E., \& Amor, P. J. (in press). Adolescents Adjudicated for Sexual Offending: Differences Between Sexual Reoffenders and Sexual Non-Reoffenders. Journal of Interpersonal Violence. https://doi.org/10.1177/08862605211015209 


\section{Table 1}

\section{Family Characteristics and Background}

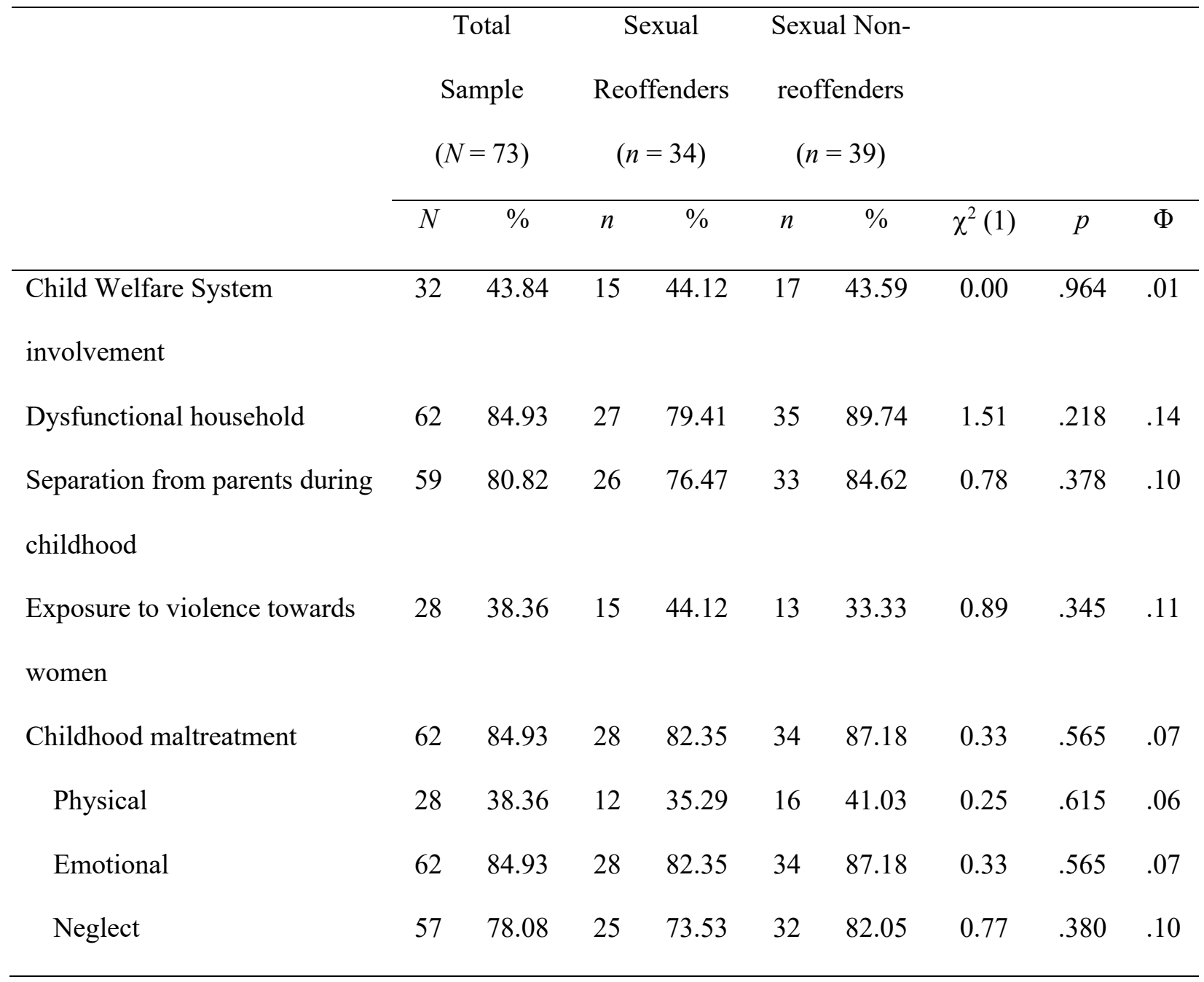

Note. $\Phi=$ phi coefficient ( $2 \times 2$ crosstabs). Data indicate the presence of each variable as all the variables were dichotomously categorized (presence/absence).

Siria, S., Echeburúa, E., \& Amor, P. J. (in press). Adolescents Adjudicated for Sexual Offending: Differences Between Sexual Reoffenders and Sexual Non-Reoffenders. Journal of Interpersonal Violence. https://doi.org/10.1177/08862605211015209 


\section{Table 2}

School Related, Antisocial Behavior, Mental Illness, and Substance Abuse Characteristics

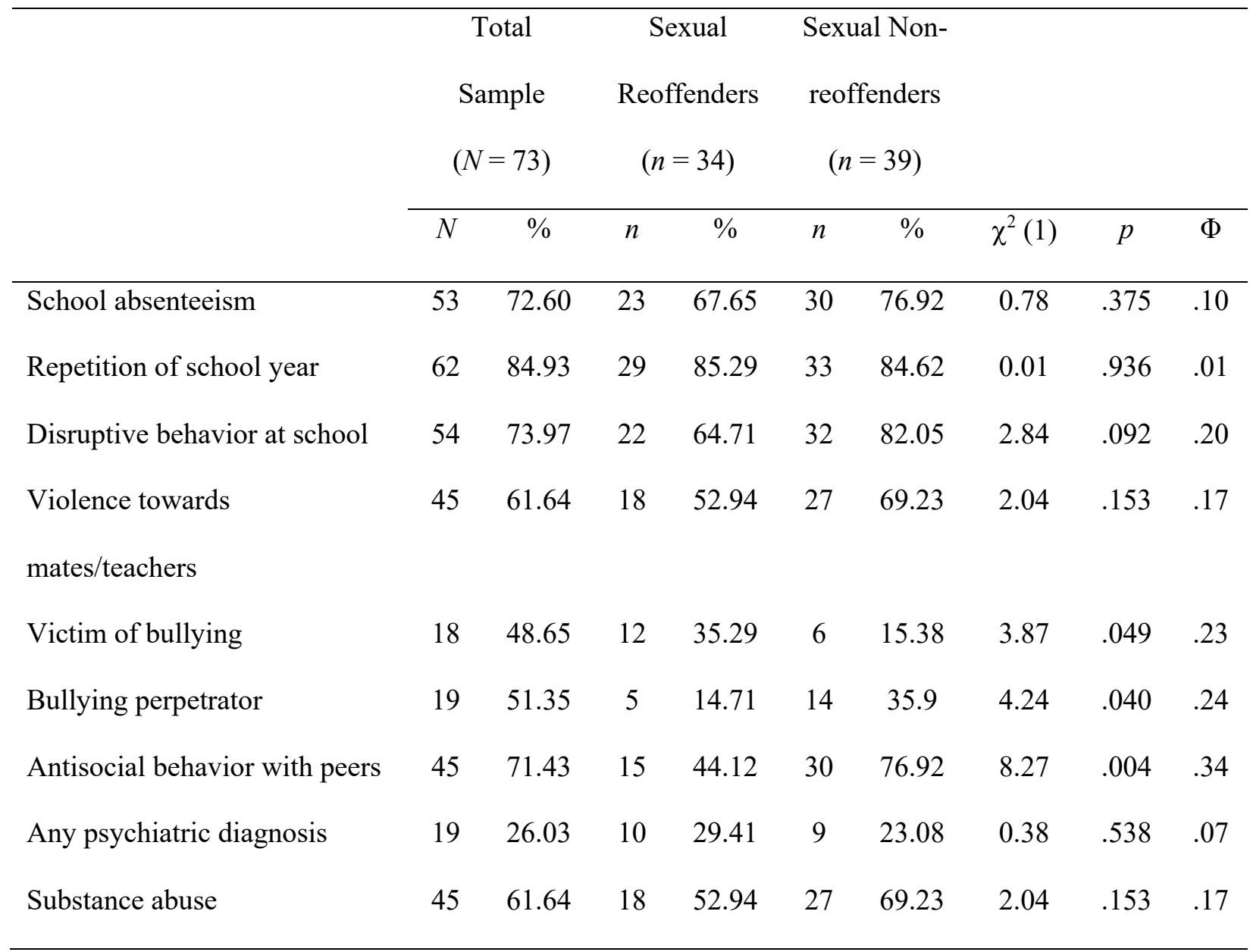

Note. $\Phi=$ phi coefficient $(2 \times 2$ crosstabs). Data indicate the presence of each variable as all the variables were dichotomously categorized (presence/absence).

Siria, S., Echeburúa, E., \& Amor, P. J. (in press). Adolescents Adjudicated for Sexual Offending: Differences Between Sexual Reoffenders and Sexual Non-Reoffenders. Journal of Interpersonal Violence. https://doi.org/10.1177/08862605211015209 


\section{Table 3}

Sexual Behavior and Sexual Development Variables

\begin{tabular}{|c|c|c|c|c|c|c|c|c|c|}
\hline & \multicolumn{2}{|c|}{$\begin{array}{l}\text { Total } \\
\text { Sample } \\
(N=73)\end{array}$} & \multicolumn{2}{|c|}{$\begin{array}{c}\text { Sexual } \\
\text { Reoffenders } \\
(n=34)\end{array}$} & \multicolumn{2}{|c|}{$\begin{array}{l}\text { Sexual Non- } \\
\text { reoffenders } \\
\quad(n=39)\end{array}$} & \multirow[b]{2}{*}{$\chi^{2}(1)$} & \multirow[b]{2}{*}{$p$} & \multirow[b]{2}{*}{$\Phi$} \\
\hline & $N$ & $\%$ & $n$ & $\%$ & $n$ & $\%$ & & & \\
\hline Previous partner relationship & 67 & 91.78 & 30 & 88.24 & 37 & 94.87 & 0.36 & .547 & .12 \\
\hline Previous sexual intercourse & 56 & 76.71 & 20 & 58.82 & 36 & 92.31 & 11.40 & .001 & .39 \\
\hline $\begin{array}{l}\text { Had a partner when committed } \\
\text { sexual crime }\end{array}$ & 22 & 30.14 & 6 & 17.65 & 16 & 41.03 & 4.71 & .030 & .25 \\
\hline $\begin{array}{l}\text { Inappropriate family sexual } \\
\text { behavior }\end{array}$ & 19 & 26.03 & 15 & 44.12 & 4 & 10.82 & 10.82 & .001 & .38 \\
\hline $\begin{array}{l}\text { Early pornography } \\
\text { consumption }(\leq 12)\end{array}$ & 51 & 69.86 & 25 & 73.53 & 26 & 66.67 & 0.41 & .052 & .07 \\
\hline Victim of sexual violence & 16 & 21.92 & 14 & 41.18 & 2 & 5.13 & 13.79 & .000 & .43 \\
\hline Deviant sexual fantasies & 15 & 20.55 & 15 & 44.12 & 0 & 0 & 21.65 & .000 & .54 \\
\hline $\begin{array}{l}\text { Early consensual sexual } \\
\text { intercourse }(\leq 13)\end{array}$ & 31 & 42.46 & 9 & 26.47 & 22 & 56.41 & 6.66 & .010 & .30 \\
\hline
\end{tabular}

Note. $\Phi=$ phi coefficient $(2 \times 2$ crosstabs $)$. Data indicate the presence of each variable as all the variables were dichotomously categorized (presence/absence).

Siria, S., Echeburúa, E., \& Amor, P. J. (in press). Adolescents Adjudicated for Sexual Offending: Differences Between Sexual Reoffenders and Sexual Non-Reoffenders. Journal of Interpersonal Violence. https://doi.org/10.1177/08862605211015209 


\section{Table 4}

Sexual Crime Characteristics

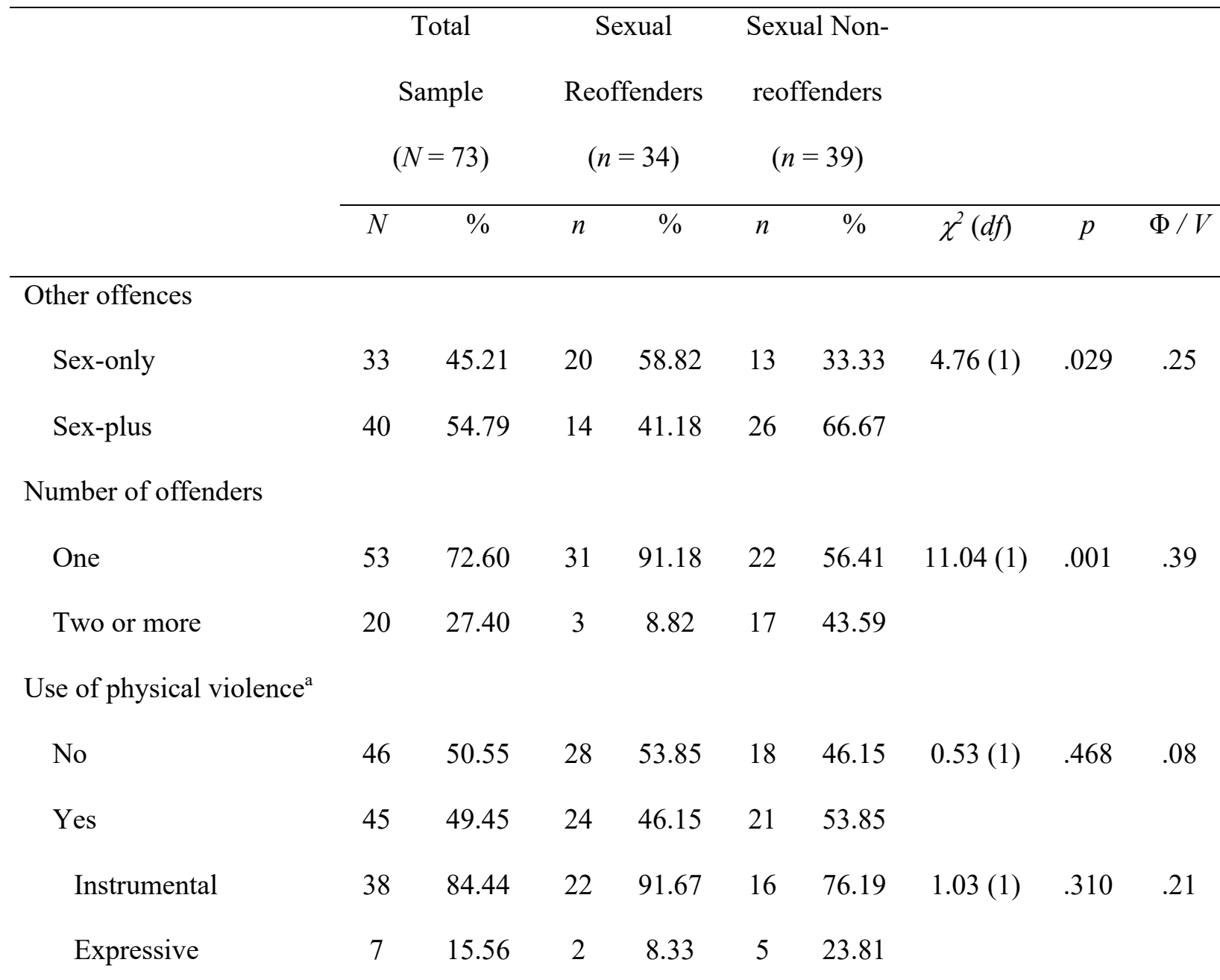

Place of the offence ${ }^{\mathrm{a}}$

$\begin{array}{lccccccccc}\text { Public } & 49 & 53.85 & 29 & 55.77 & 20 & 51.28 & 0.22(2) & .895 & .05 \\ \text { Private } & 38 & 41.76 & 21 & 40.38 & 17 & 43.59 & & & \\ \text { Internet } & 4 & 4.39 & 2 & 3.85 & 2 & 5.13 & & & \end{array}$

Victim approach ${ }^{\mathrm{a}}$

$\begin{array}{llllllllll}\text { Planned } & 44 & 48.35 & 40 & 76.92 & 4 & 10.26 & 39.66(1) & .000 & .66 \\ \text { Impulsive } & 47 & 51.65 & 12 & 23.08 & 35 & 89.74 & & & \end{array}$

Siria, S., Echeburúa, E., \& Amor, P. J. (in press). Adolescents Adjudicated for Sexual Offending: Differences Between Sexual Reoffenders and Sexual Non-Reoffenders. Journal of Interpersonal Violence. https://doi.org/10.1177/08862605211015209 
Victim gender

$\begin{array}{lccccccccc}\text { Female } & 55 & 75.34 & 22 & 64.71 & 33 & 84.62 & 5.48(2) & .064 & .27 \\ \text { Male } & 15 & 20.55 & 9 & 26.47 & 6 & 15.38 & & & \\ \text { Both } & 3 & 4.11 & 3 & 8.82 & 0 & 0 & & \end{array}$

Victim age ${ }^{\mathrm{a}}$

$\begin{array}{llllllllll}\text { Child } & 31 & 34.06 & 26 & 50 & 5 & 12.82 & 15.13(2) & .000 & .41 \\ \text { Peer } & 49 & 53.85 & 23 & 44.23 & 26 & 66.67 & & & \\ \text { Adult } & 11 & 12.09 & 3 & 5.77 & 8 & 20.51 & & \end{array}$

Victim relationship ${ }^{\mathrm{a}}$

$\begin{array}{lccccccccc}\text { Family } & 16 & 17.58 & 14 & 26.92 & 2 & 5.13 & 7.42(2) & .024 & .28 \\ \text { Acquaintance } & 42 & 46.15 & 22 & 42.31 & 20 & 51.28 & & & \\ \text { Unknown } & 33 & 36.27 & 16 & 30.77 & 17 & 43.59 & & \end{array}$

Note ${ }^{\text {a }}$ Variables accounted by number of sexual crimes $(n=91)$, not by participants: sexual reoffenders group included 52 sexual crimes and sexual non-reoffenders group 39. $\Phi=$ phi coefficient $(2 \times 2$ crosstabs); $V=$ Crammer's $V$.

Siria, S., Echeburúa, E., \& Amor, P. J. (in press). Adolescents Adjudicated for Sexual Offending: Differences Between Sexual Reoffenders and Sexual Non-Reoffenders. Journal of Interpersonal Violence. https://doi.org/10.1177/08862605211015209 


\section{Table 5}

Results of Interpersonal Reactivity Index (IRI)

\begin{tabular}{|c|c|c|c|c|c|c|c|c|c|}
\hline & \multicolumn{2}{|c|}{ Total } & \multicolumn{2}{|c|}{ Sexual } & \multicolumn{2}{|c|}{ Sexual Non- } & & & \\
\hline & \multicolumn{2}{|c|}{ Sample } & \multicolumn{2}{|c|}{ Reoffenders } & \multicolumn{2}{|c|}{ reoffenders } & & & \\
\hline & & & & & & & & & \\
\hline & $M$ & $S D$ & $M$ & $S D$ & $M$ & $S D$ & $t$ & $p$ & $d$ \\
\hline Total score & 60.58 & 10.38 & 60.12 & 11.19 & 60.97 & 9.74 & 0.35 & .729 & .08 \\
\hline Perspective taking & 15.84 & 5.14 & 14.85 & 5.71 & 16.69 & 4.48 & 1.54 & .127 & .36 \\
\hline Fantasy & 13.90 & 5.53 & 14.68 & 5.79 & 13.23 & 5.28 & 1.12 & .266 & .26 \\
\hline Empathic concern & 19.25 & 5.13 & 18.59 & 5.57 & 19.82 & 4.72 & 1.02 & .311 & .24 \\
\hline Personal distress & 11.59 & 4.20 & 12.00 & 3.87 & 11.23 & 4.49 & 0.78 & .438 & .18 \\
\hline
\end{tabular}

Note. $d=$ Cohen's $d$. Total score range: 0-112. Subscales' score range: 0-28.

Siria, S., Echeburúa, E., \& Amor, P. J. (in press). Adolescents Adjudicated for Sexual Offending: Differences Between Sexual Reoffenders and Sexual Non-Reoffenders. Journal of Interpersonal Violence. https://doi.org/10.1177/08862605211015209 